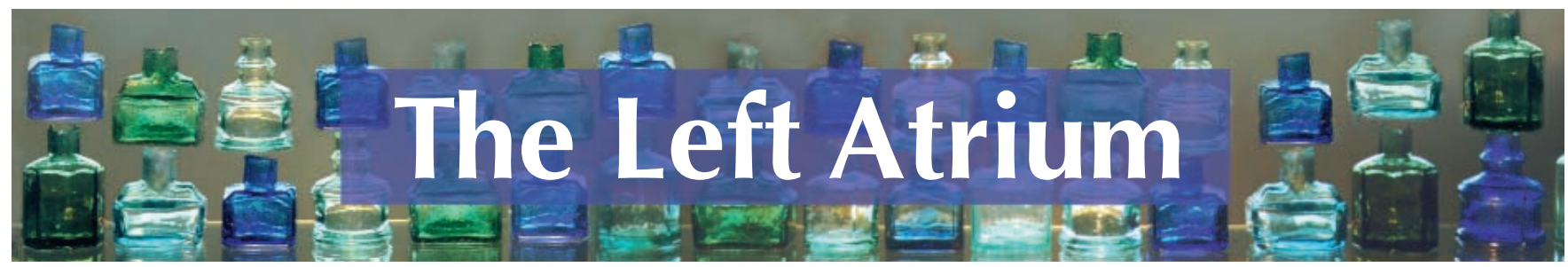

\section{Covenants and compromises}

On the take: how medicine's complicity with big business can endanger your health Jerome P. Kassirer

New York: Oxford University Press; 2004

272 pp $\$ 44.95$ (cloth) ISBN 0-1951-7684-7

The last well person: how to stay well despite the health-care system

Nortin M. Hadler

Montréal: McGill-Queen's University Press; 2004

320 pp \$39.95 (cloth) ISBN 0-7735-2795-8

I

love pithy phrases. American sociologist Robert Bellah coined one of my favourites in The Broken Covenant, his 1975 discussion of American "civil religion." Of America's pilgrim founders he wrote, "[T]hey came to do good, and did well." Bellah argued that the American colonists came to see success in their "new" land as a sign of God's favour; a covenant was said to exist, wherein the new nation's prosperity — doing well was bestowed by God as a reward for doing good. Bellah's contention was that this putative covenant had been broken (and perversely reversed) by the belief that, regardless of how the nation was behaving, continuing prosperity proved its behaviour to be good.

Few would dispute that we physicians do well - regardless, arguably, of the degree to which we do good. And few among us would deny that the prospect of "doing well" had at least some bearing on our decision to enter medicine; most of us, I'll wager, hope to do well and good. But to what extent do the abundant privileges that accrue to our station as physicians influence our behaviour? Can the desire to do well be in conflict with the desire to do good? I've always found these questions somewhat unsettling, but it's worse these days when, as a money-earning resident, I write my notes with a "sponsored" pen, guiltily savour free lunches, and fantasize about a new car.

I've just read two new books that add to my disquiet. On the Take: How Medicine's Complicity with Big Business Can Endanger Your Health is a no-holdsbarred exposé by Jerome Kassirer, former editor-in-chief of the New England Journal of Medicine. Kassirer suggests that many or most physicians have been corrupted by filthy lucre, and that most of the research on which physicians ostensibly base their practice is at best compromised and at worst deliberately deceptive. American rheumatologist Nortin Hadler raises the ante somewhat in The Last Well Person: How to Stay Well Despite the Health-care System; he argues that "medicine" in general has come to represent as much a threat as a boon to the health of Americans (and thus, one assumes, Canadians).

Each of these books has an Oprahworthy title, and each delivers a degree of anticipated sensationalism. Here is Kassirer: " $[\mathrm{M}]$ oney talks for physicians as it does for us all," and, furthermore, "too many physicians have become marketing whores, mere tools of industry's promotional efforts." Hadler is less bombastic but possibly more heretical: "Even those of you who are convinced you are well must continually withstand badgering assaults from a variety of health promoters." Elsewhere, and repeatedly, Hadler warns of health care providers who "medicaliz[e] 'healthy individuals' so that they grasp at unproven remedies for contrived diseases that are said to be life-threatening."
The difference in tone between these two books is significant and not accidental. Where Kassirer appears to chastise his colleagues, meaning to shame and thereby change them, Hadler seems to have given up on physicians and instead addresses his treatise to health care "consumers," in particular those who are well. But both Kassirer and Hadler see the terms "marketing" and "consumers" as problematic in health care; if either author could be said to feel that a covenant may once have existed between the medical profession and its constituency, he would surely see it as broken to the extent that health and wellness have become commodities and physicians their purveyors.

Notwithstanding a degree of moralizing in their books, these authors are to be credited for weighing in on some vexing problems. Kassirer presents a number of well-known arguments and points out more than a few situations in which modern medicine, the doctors who practise it, and the institutions within which they do so can at least appear to be compromised by financial relationships with big businesses. And, let's not be coy, the big businesses are the pharmaceutical giants:

Pharmaceutical companies have learned that their profits are at least as dependent on their marketing efforts as the power of their scientific accomplishments, and they have pumped money into physicians' pockets .... This enormous infusion of money has yielded financial incentives that many physicians find difficult to ignore.

It is obvious, however, that the complexities and nuances of the relationship between big business and medicine have not escaped Kassirer. A confession of sorts provides him with both a soapbox and the moral authority to use it (and goes some way to explaining his zeal). He relates a personal epiphany, through which it began to dawn on him that, when drug company representatives offered to add him to a list of ${ }^{\frac{\omega}{\omega}}$ 
speakers and give him an honorarium, there were strings attached. He goes to great lengths to explain that it took several years for the strings to become visible, and that, before they did, he enjoyed the "welcome addition to a rather meager fixed academic salary." But when that same company began to insist that he mention their new drug at least once in each of his talks, Kassirer "felt uncomfortable with what seemed like a questionable practice" and ended his relationship with the pharmaceutical giant.

Kassirer appropriately observes that, taking the long view, the pharmaceutical industry has "produced medications that have extended life, prevented serious illnesses, and improved the quality of life of millions of people." But On the Take is replete with examples of apparent financial conflicts of interest. There are descriptions of Big Pharma substantially supporting (i.e., directing) major

\section{Romeo's eyes}

Your eyes looked until you could bear see no more how rotting corpses piled high on a church doorstep the ash-faced priest for dearest butchered orphans he weeps;

your help he pleads

but Blue Beret, you only stand

and cover mouth with kerchiefed hand.

While the crushing calm of the morning

re-invigorates the Kigali starling, sing! bird, sing! til your troubled throat bursts 'round the génocidaire Hutu who wipes clean his alibi - the pungent machete's bloody glean.

The sister-hunter resumes his relentless tempo of daily kills, Our Father who art prays Romeo, with clenched jaw and fist the prayer that falls on deafened ears, the First World's heart cuts

the strings that tie your eye to a Tutsi mother, her mutilated breasts serve the media fodder while her baby, immortal survivor flares across your face, a supernova from the sky.

\section{Normand Carrey}

Psychiatrist

Halifax, NS randomized controlled trials (Nancy Olivieri is mentioned), bank-rolling continuing medical education and lining the pockets of greedy physicians unable to stand up to the nefarious marketing of detail teams.

Nevertheless, I think Kassirer's concerns are less financial than fiduciary, less pecuniary than about probity. He emphasizes the perhaps forgotten ideas that patients "should not have to worry about the integrity of their doctors" and that "medicine depends on the public's trust for its viability." Explicit throughout his book is the intuitive suggestion that, if financial conflicts of interest appear to exist, they $d_{0}$ exist. Which is to say that, if patients believe they have reasons to question the motives of their physicians, the all-important physician-patient relaionship is compromised.

Thus it is that Kassirer, now confessed and implicitly redeemed, appears to understand that "financial conflicts ... are optional [and that] an individual can choose to have a financial conflict or to avoid one" but sees us all as vulnerable nonetheless. He devotes the last chapter of his well-referenced book to some suggestions by which conflicts of interest might be attenuated, and perhaps prevented from leading to outright corruption. Most involve tighter regulations, more control and increased oversight in short, bigger, more cumbersome and expensive infrastructure (the funding for which would come from ...?). The irony is not lost on Kassirer that "[i]n 2001 the AMA launched a $\$ 645000$ educational campaign to convince physicians not to accept gifts from pharmaceutical companies" but funded the campaign with grants from the very same.

Having faced his own vulnerability, and aggravated by what he takes to be the selling-out of many of his colleagues, Kassirer is frustrated, and his book frustrating. Because, as a wise physician once told my class, although money can't buy happiness, it's nice to have it when you go shopping. And it has to come from somewhere. I am writing in the basement of a dated, drab and dingy Canadian hospital, while above me - in the name of equal access to a publicly funded system - patients wait for hours to be seen by an emergency physician for a (usually) non-emergent problem. All of which brings me back to Hadler, whose book rehearses an argument no less familiar than Kassirer's: most of the time, most people don't need most doctors.

Hadler's thinking is informed by two relatively well-argued ideas. The first stems from a point made by Kassirer: "most of the top medical authorities ..., and virtually all the top medical speakers on medical topics, are employed in some capacity by one or more of the country's pharmaceutical companies." It surely has not escaped anyone's notice that much medical research is feasible only to the extent that it is underwritten by large multinational corporations with so much obviously riding on its outcome. Hadler bemoans a "medical literature scarred by vested interests" and attempts to disabuse his readers of the pervasive and arguably mistaken belief that there is good evidence to support the broad application of such things as CABG for angina; cholesterol, blood pressure, and blood glucose monitoring; and screening for colon, breast and prostate cancer.

In addressing each of these areas, Hadler critiques the so-called landmark studies on which current practices are based. But lest he be made to sound altogether too like a quack, it is important to reiterate that his target audience is composed of well individuals; his book doesn't purport to tell people how to get well, but how to stay well. For example, although he notes "there are serious questions whether statin treatment affords any meaningful advantages 
to people who have not had a heart attack," he does not suggest that those who have had a heart attack ought to discontinue their lipid-lowering drugs. Hadler's warning to the well is that the aggressive marketing of medications, aimed at patients and physicians alike, often fails to mention that the research on which its claims are based was conducted on a population of people quite unlike themselves (i.e., sick people). Hadler also wants his readers to know that data from secondary prevention studies cannot necessarily be extrapolated to primary prevention; that is, just because "studies" have shown that my grandfather who had a myocardial infarction might benefit from taking an aspirin a day, it does not follow that I will benefit from taking an aspirin with my morning caffeine.

Having said that, if I have a headache, caffeine and aspirin (or acetaminophen) might be just the ticket. And this brings me to the second, more compelling, theme of Hadler's book. "We cannot live," he writes,

without heartache and backache, heartburn and headache, unfamiliar bowel function, peculiar sensations, days in the doldrums, realizations of physical limits, and myriad other predicaments.

Hadler bemoans the thinking that has "elevated medicine to be the arbiter of normalcy," and he is at pains to convince his readers, in the face of much "information" to the contrary, that to "be well is to be able to cope with morbid episodes," not to be free of symptoms.

Not every symptom, that is, needs to be fixed or even investigated. I think I would be hard pressed to find a physician to disagree with this. But in a manner not unlike Kassirer's, Hadler seems to imply that many of us lack the ability to appreciate nuance. It is his somewhat bitter-sounding contention that we all are held captive by "the belief that there must be a disease underlying every illness, [and are] seduc[ed] to assume that any demonstrable coincident abnormality, or difference, is the likely culprit." Be wary of your doctor, he suggests, lest he or she dangerously insist on fixing what isn't broken.
Now, to be fair (if a little defensive), I am fortunate to be part of a clinic (and I hope a community) where the distinction between illness and disease is understood, and indeed where kind reassurance and gentle handholding are valued as therapeutic manoeuvres. Although Hadler warns that a "physician can arrange a cardiac catheterization far more readily than [she or] he can manage the considerable time to discuss why it may not be necessary," I wonder, as I did throughout his book, whether it is patients or physicians who drive the medicalizing machine.

To be sure, it's a chicken-and-egg sort of conundrum. I'm tempted to take the easy way out and blame the big drug companies (even as I eat their sandwiches). More likely, though, I think I will continue to muddle my way through grey ambiguities, while I struggle to render the "evidence" from large (arguably compromised) population studies germane to the lives of my individual patients, many of whom I need more than they need me.

\section{Edward E. St. Godard \\ PGY1 \\ Family Medical Centre \\ University of Manitoba \\ Winnipeg, Man.}

\section{Une heureuse union}

went into her room and was asked, "What's the French for 'gallbladder'?" The nice francophone lady with the positive Murphy sign had been trying to explain her problem to her husband. He'd been at her bedside since she was admitted, wearing a look of tender concern the whole time. But he had less English than she did and had not understood our explanations of what was the matter.

Later I realized that if she couldn't name the organ in her first language, she likely hadn't understood what "gallbladder" meant, either. At the time, though, all I could think was, "What's the French for 'gallbladder.' I dunno ... le gallbladder?" Four and a half years of high school French, and this was my best guess.

Looking for an excuse, any excuse, not to go to the OR to watch one more laparoscopic cholecystectomy, I decided to find the answer. There was a francophone nurse on the ward, but she wasn't working that day. One of the custodial staff spoke some French, but not enough: he said he'd call his grandfather and ask him. I protested, feebly, that this was not important enough to bother anyone's Grampa about. But when the guy came back with his grandfather's answer, I happily thanked him for it.

On my way back to my patient's room, I practised pronunciation in my head. I delivered a pre-emptory apology for whatever injury I was about to do to their language and then told them how to say "gallbladder" in French.

The husband's face lit up with long-awaited understanding. "Ahhh ... vésicule biliare!" he exclaimed. He then turned to his wife, and his expression changed from happy comprehension to the sweet worry I was used to seeing. A moment later, though, his face changed again. I found his new expression to be strangely comforting; I guessed that it marked the return of some of the normalcy that had been taken from their marriage by her illness.

It was an apparently well-practised look of mild annoyance. It seemed to say, in French even I could understand, "Well, why didn't you just say that?"

\section{Paul Moorehead}

Pediatrics Resident

Memorial University of Newfoundland

St. John's, Nfld. 